
КУЛЬТИВИРОВАНИЯ ЛЕЙКОЗНЫХ Т-ЛИМФОБЛАСТОВ

\author{
Литвинова Л.С. ${ }^{1}$, Юрова К.А. ${ }^{1}$, Шуплецова В.В. ${ }^{1}$, \\ Газатова Н.Д. ${ }^{\text {, }, ~ Х а з и а х м а т о в а ~ О . Г . ~}{ }^{1}$, Малащенко В.В. ${ }^{1}$, \\ Шунькин Е.О. ${ }^{1}$, Тодосенко Н.М. ${ }^{1}$, Мелащенко Е.С. ${ }^{1}$, Хлусова М.Ю. \\ Хлусов И.А. ${ }^{1,2,3}$ \\ ${ }^{1}$ ФГАОУ ВО «Балтийский федеральный университет имени И. Канта», г. Калининград, Россия
${ }^{2}$ ФГБОУ ВО «Сибирский государственный медицинский университет», г. Томск, Россия
${ }^{3}$ ФГАОУ ВО «Национальный исследовательский Томский политехнический университет», г. Томск, Россия
}

Резюме. Правильный выбор питательных сред для культивирования различных видов клеток в разнообразных приложениях является одним из важнейших аспектов современных биотехнологий, поскольку химический состав культуральных сред во многом воспроизводит необходимые метаболиты для поддержания роста определённых линий клеток вне организма. Jurkat линия лейкозных Т-лимфобластоподобных клеток человека (далее Jurkat Т-клетки) активно используется для in vitro моделирования внутриклеточного сигналинга и активации нормальных Т-лимфоцитов крови, опосредованной комплексом Т-клеточный рецептор/CD3/CD4, в токсикологических исследованиях иммунных и секреторных реакций на лекарственные вещества и ионы. Кроме того, Jurkat T-клетки широко применяются для ex vivo тестирования в области иммунологии, онкологии, токсикологии, ортопедии и травматологии. Существующие стандарты и многочисленные исследования основаны преимущественно на краткосрочном in vitro культивировании Jurkat T-клеток в питательной среде RPMI 1640. Вместе с тем вопросы длительного обеспечения роста культуры Jurkat T-клеток слабо представлены в научной литературе. Целью данного исследования явилось изучение активности Jurkat Т-клеток в 7-14-суточной культуре in vitro и сравнительная оценка значения RPMI 1640 и $\alpha$ MEM для поведения иммунокомпетентных опухолевых клеток. C помощью проточной цитофлуориметрии, мультиплексного анализа и фазово-контрастной Cell-IQ микроскопии изучены доли живых и погибших клеток путем апоптоза и некроза, секреция цитокинов и хемокинов, динамика накопления клеточной биомассы. Установлено, что среда $\alpha$ МЕМ в составе полной питательной среды, в сравнении с RPMI 1640, в большей мере способствует in vitro поддержанию жизнеспособности (увеличение доли живых клеток на 13,5\% к 14-м суткам), секреторной способности в отношении 23 из 27 тестируемых биомолекул, сокращению (на $32 \%$ ) времени адаптации клеток к условиям культивирования перед пролиферацией, 5-кратному приросту клеточности культуры Jurkat T-клеток к 7-м суткам. Обсуждается потенциальное значение химических компонентов питательных сред и секретируемых биомолекул для полученных результатов. На основании полученных результатов сделано заключение о более

Адрес для переписки:

Литвинова Лариса Сергеевна

ФГАОУ ВО «Балтийский федеральный университет имени И. Канта»

236000, Россия, г. Калининград, ул. Гайдара, 6. Тел.: 8(4012) 59-55-95 (доб. 6631).

E-mail: larisalitvinova@yandex.ru

\section{Образец цитирования:}

Л.С. Литвинова, К.А. Юрова, В.В. Шуплецова, Н.Д. Газатова, О.Г. Хазиахматова, В.В. Малащенко, Е.О. Шунькин, Н.М. Тодосенко, Е.С. Мелащенко, М.Ю. Хлусова, И.А. Хлусов «Значение выбора питательной среды для результатов длительного іп vitro культивирования лейкозных Т-лимфобластов» // Медицинская иммунология, 2021. T. 23, № 3.

C. 593-604. doi: 10.15789/1563-0625-SON-2142

(С) Литвинова Л.С. и соавт., 2021
Address for correspondence:

Litvinova Larisa $S$.

I. Kant Baltic Federal University

236000, Russian Federation, Kaliningrad, Gaidar str., 6.

Phone: 7 (4012) 59-55-95 (acc. 6631).

E-mail: larisalitvinova@yandex.ru
For citation:

L.S. Litvinova, K.A. Yurova, V.V. Shchupletsova,

N.D. Gazatova, O.G. Khaziakhmatova, V.V. Malashchenko,

E.O. Shunkin, N.M. Todosenko, E.S. Melashchenko,

M.Yu. Khlusova, I.A. Khlusov "Significance of nutrient media choice for the long-term cultures of leukemic T-lymphoblasts”, Medical Immunology (Russia)/Meditsinskaya Immunologiya, 2021, Vol. 23, no. 3, pp. 593-604.

doi: $10.15789 / 1563-0625-S O N-2142$

DOI: $10.15789 / 1563-0625-\mathrm{SON}-2142$ 
оптимальных свойствах среды $\alpha$ МЕМ для длительного in vitro культивирования Jurkat Т-клеток. Как следствие, тестирование in vitro медицинских изделий, предназначенных для долговременного контакта с организмом, в том числе у онкологических больных, на лейкозной линии Jurkat T-клеток в среде RPMI 1640 могут обусловить ошибочный прогноз их биосовместимости и потенциальной противоопухолевой активности.

\title{
SIGNIFICANCE OF NUTRIENT MEDIA CHOICE FOR THE LONG-TERM CULTURES OF LEUKEMIC T-LYMPHOBLASTS
}

\author{
Litvinova L.S. ${ }^{\text {a }, ~ Y u r o v a ~ K . A . ~}{ }^{\text {a }}$, Shchupletsova V.V. ${ }^{\text {, }}$ \\ Gazatova N.D. ${ }^{a}$, Khaziakhmatova O.G. ${ }^{a}$, Malashchenko V.V., \\ Shunkin E.O. a, Todosenko N.M. ${ }^{a}$, Melashchenko E.S. ${ }^{a}$, Khlusova M.Yu. \\ Khlusov I.A. ${ }^{\mathrm{a}, \mathrm{b}, \mathrm{c}}$
}

\author{
${ }^{a}$ I. Kant Baltic Federal University, Kaliningrad, Russian Federation \\ ${ }^{b}$ Siberian State Medical University, Tomsk, Russian Federation \\ c Tomsk Polytechnic University, Tomsk, Russian Federation
}

\begin{abstract}
Correct choice of nutrient media for culturing different types of cells in various applications is one of the most important aspects of modern biotechnology, since chemical composition of the culture media largely contains the necessary metabolites to support certain cells' growth lines outside the body. Jurkat line of human leukemic T-lymphoblast-like cells (hereinafter Jurkat T-cells) is actively used for in vitro modeling of intracellular signaling and activation of normal blood T-lymphocytes mediated by the T-cell receptor/CD3/ CD4 complex in toxicological studies of immune and secretory responses, to test medicinal substances and ions. Also, Jurkat T-cells are widely used for ex vivo testing in immunology, oncology, toxicology, orthopedics, and traumatology. The existing standards and numerous studies are mainly based on short-term in vitro cultivation of Jurkat T-cells in RPMI 1640 nutrient medium. Meanwhile, the issues of long-term maintenance of the growth of Jurkat T-cells culture are poorly presented in the research literature. This study aimed for studying the activity of Jurkat T-cells over 7 to 14 days of in vitro culture and comparing the relative value of RPMI 1640 and $\alpha$ MEM media for the behavior of immunocompetent tumor cells. Using flow cytometry, multiplex analysis, and phase contrast Cell-IQ microscopy, the proportions of living cells and those dying by apoptosis and necrosis, secretion of cytokines and chemokines, and the dynamics of cell biomass propagation were studied. It was found that the $\alpha$ MEM medium in the complete nutrient medium, as compared with RPMI 1640, is more appropriate to in vitro promotion of cell viability (increased proportion of viable cells by $13.5 \%$ at the day 14), their secretory ability for 23 из 27 tested biomolecules, shortened adaptation time (на 32\%) in culture before growth initiation, 5-fold increase of the Jurkat T-cell cellularity by the day 7. Potential significance of the chemical components of nutrient media and secreted biomolecules for these results is discussed. As based on the results obtained, we concluded on superior properties of $\alpha$ MEM medium for long-term in vitro cultures of Jurkat T-cells. Consequently, the in vitro testing of medical devices intended for long-term contact with the body, including those for cancer patients, using Jurkat T-cell leukemia line in RPMI 1640 medium, may lead to wrong predictions on their biocompatibility and potential antitumor activity.
\end{abstract}

Keywords: RPMI 1640, aMEM, Jurkat T cells, viability, secretion, Cell-IQ monitoring

Работа выполнена при финансовой поддержке Российского научного фонда (проект 16-1510031; оценка цитокинового профиля и Cell-IQ визуализация клеток в разных условиях культивирования), а также государственной поддержке ведущих научных школ РФ (НШ-2495.2020.7; оценка процессов апоптоза и некроза клеток).

\section{Введение}

Jurkat линия лейкозных Т-лимфобластоподобных клеток человека (далее Jurkat Т-клетки) активно используется в изучении Т-клеточного лимфолейкоза и лимфом [12], терапевтического эффекта противоопухолевых препаратов [20]. 
С другой стороны, Jurkat Т-клетки применяются для in vitro моделирования внутриклеточного сигналинга и активации нормальных Т-лимфоцитов крови, опосредованной комплексом Т-клеточный рецептор/CD3/CD4, в токсикологических исследованиях иммунных и секреторных реакций на токсические вещества и ионы, наночастицы и биомедицинские материалы [4, 5, 7, 10, 17, 22, 26, 27].

В то же время существующие стандарты (ГОСТ ISO 10993-5) и многочисленные исследования основаны, преимущественно, на краткосрочном (обычно не более 72 ч) in vitro культивировании клеток [14, 15, 25, 28]. Как следствие, исследователи получают неполную информацию о динамике роста клеточной популяции и механизмах ее реакции на раздражители. В случае тестирования медицинских изделий, предназначенных для долговременного контакта с организмом, в том числе у онкологических больных, результаты краткосрочного эксперимента могут обусловить ошибочный прогноз их биосовместимости и специфической активности.

Цитокины и хемокины являются важнейшими биомолекулами, регулирующими поведение и взаимодействие клеток ауто-, пара- и эндокринным способом [3]. Вместе с тем вопросы длительного обеспечения роста культуры Jurkat T-клеток слабо представлены в научной литературе. В связи с этим целью данного исследования явились изучение активности Jurkat Т-клеток в 7-14-суточной культуре in vitro и сравнительная оценка значения культуральной среды для поведения иммунокомпетентных опухолевых клеток.

\section{Материалы и методы}

\section{Варианты культивирования клеток}

Культивирование $1 \times 10^{6}$ жизнеспособных Jurkat Т-клеток (Российская коллекция клеточных культур позвоночных, Институт цитологии PAН, г. Санкт-Петербург) в 1 мл полной питательной среды (ППС) проводили при $37^{\circ} \mathrm{C}$, во влажной атмосфере, содержащей $5 \% \mathrm{CO}_{2}$ в течение 2 суток в 24-луночных планшетах или в течение 14 суток - в 12-луночных планшетах (Orange Scientific, Бельгия). Среда RPMI 1640 (Roswell Park Memorial Institute) без L-глютамина (кат. номер: 31870025; Gibco Life Technologies, Великобритания) содержала также следующие добавки: $10 \%$ инактивированной $\left(56{ }^{\circ} \mathrm{C}\right.$ в течение 30 мин) сыворотки крови эмбрионов коров (ЭТС; кат. номер: A3160802; Gibco, Германия), 280 мг/л L-глютамина (Sigma-Aldrich, США), 100 Е мкг/мл пенициллина/стрептамицина (Gibco Life Technologies, США), применялась для всех сроков культивирования. ППС на основе $\alpha \mathrm{MEM}$ (Minimum Essential Media) без глютамина и (дезокси)рибонуклеозидов (кат. номер: М4526; Sigma-Aldrich, США) использовалась с анало- гичными добавками (ЭТС, глутамин, антибиотики) параллельно с RPMI 1640 при 7-14-суточном культивировании. При культивировании клеток свыше 2 дней ППС меняли каждые 3-4 суток.

\section{Проточная цитофлуориметрия}

После 2-х и 14-х суток культивирования собирали неприлипающие клетки, супернатанты отделяли от клеточной взвеси центрифугированием в течение 10 мин при 1500 об/мин. Клеточную взвесь подвергали проточной цитометрии с помощью MACS Quant (Miltenyi Biotec, Германия). Жизнеспособность клеток определяли при помощи набора реагентов ANNEXIN V FITC (Abcam, США) в соответствии с инструкцией фирмыпроизводителя как описано ранее [21]. Цитофлуорометрические результаты были обработаны с применением программы KALUZA Analysis Software (Beckman Coulter, США).

В супернатантах клеточных культур с помощью мультиплексного набора (Bio-Plex Pro Human Cytokine 27-Plex Panel, Bio-Rad, СШA), двулучевого фотометра Bio-Plex Protein Assay System (Bio-Rad, CША) и программы Bio-Plex Manager (Bio-Rad, CША) оценивали спонтанную секрецию: интерлейкинов IL-1 $\beta$, IL-1ra, IL-2, IL-4, IL-5, IL-6, IL-7, IL-8, IL-9, IL-10, IL-12, IL-13, IL-15, IL-17; фактора некроза опухоли альфа (TNF $\alpha)$; гамма-интерферона (IFN $\gamma$ ); эотаксина; колониестимулирующего фактора гранулоцитов (G-CSF); колониестимулирующего фактора гранулоцитов и моноцитов (GM-CSF); гамма-интерфероном индуцируемого белка 10 (IP-10; C-X-C motif chemokine 10 (CXCL10)); моноцитарного хемотаксического протеина-1 (MCP-1; chemokine (C-C motif) ligand 2 (CCL2)); макрофагального белка воспаления $1 \alpha$ (MIP- $1 \alpha$; CCL3); макрофагального белка воспаления $1 \beta$ (MIP-1 $\beta$; CCL4); фактора, экспрессируемого и секретируемого нормальными Т-клетками при активации (RANTES; CCL5); основного фактора роста фибробластов (bFGF); фактора роста из тромбоцитов (PDGF-BB) и фактора роста эндотелия сосудов (VEGF). Концентрации цитокинов и хемокинов определяли в соответствии с инструкцией производителя и выражали в пг/мл.

\section{Фазово-контрастная Cell-IQ микроскопия}

Динамику прироста количества Jurkat Т-клеток изучали в отдельном эксперименте при 7-суточном культивировании в интегрированной платформе Cell-IQ ${ }^{\circledR}$ v2 MLF (CM Technologies Oy, Финляндия) для автоматической непрерывной фазово-контрастной микроскопии клеток в реальном времени, как описано ранее [16]. Цифровые снимки клеточной культуры (108 цифровых снимков в каждом из 6 полей зрения) получали каждые 90 мин при автоматическом включении освещения для проведения микроскопии. Каждый 10-й снимок анализировался при помощи 
программы Cell-IQ Imagen software (MI2.8.9, CM Technologies Оу, Финляния).

Начальная концентрация Jurkat Т-клеток составила $5 \times 10^{4}$ клеток в 1 мл ППС на основе RPMI 1640 или $\alpha$ MЕМ. После 7 суток культивирования возросшая биомасса неприлипающих клеток не позволила визуализировать клетки на пластиковой поверхности 12-луночного планшета (Orange Scientific, Бельгия).

\section{Статистический анализ}

При анализе полученных данных использовали возможности стандартного пакета STATISTICA for Windows версия 13.3. Нормальность распределения в выборке проверяли с помощью критерия Колмогорова-Смирнова. Рассчитывали параметры распределений: медиану $(\mathrm{Me}), 25 \%$-ный $\left(\mathrm{Q}_{0,25}\right)$ и $75 \%$-ный $\left(\mathrm{Q}_{0,75}\right)$ квартили; среднее значение $(\mathrm{X})$ и стандартное отклонение (SD). Для оценки достоверности выборок использовали непараметрические критерии Манна-Уитни (p) и Т-критерий Вилкоксона $\left(\mathrm{p}_{\mathrm{T}}\right)$ для зависимых выборок. Различия считались достоверными при уровне значимости $\mathrm{p}<0,05$.

\section{Результаты}

Согласно результатам проведенного анализа, представленным в таблице 1, длительное (в тече-
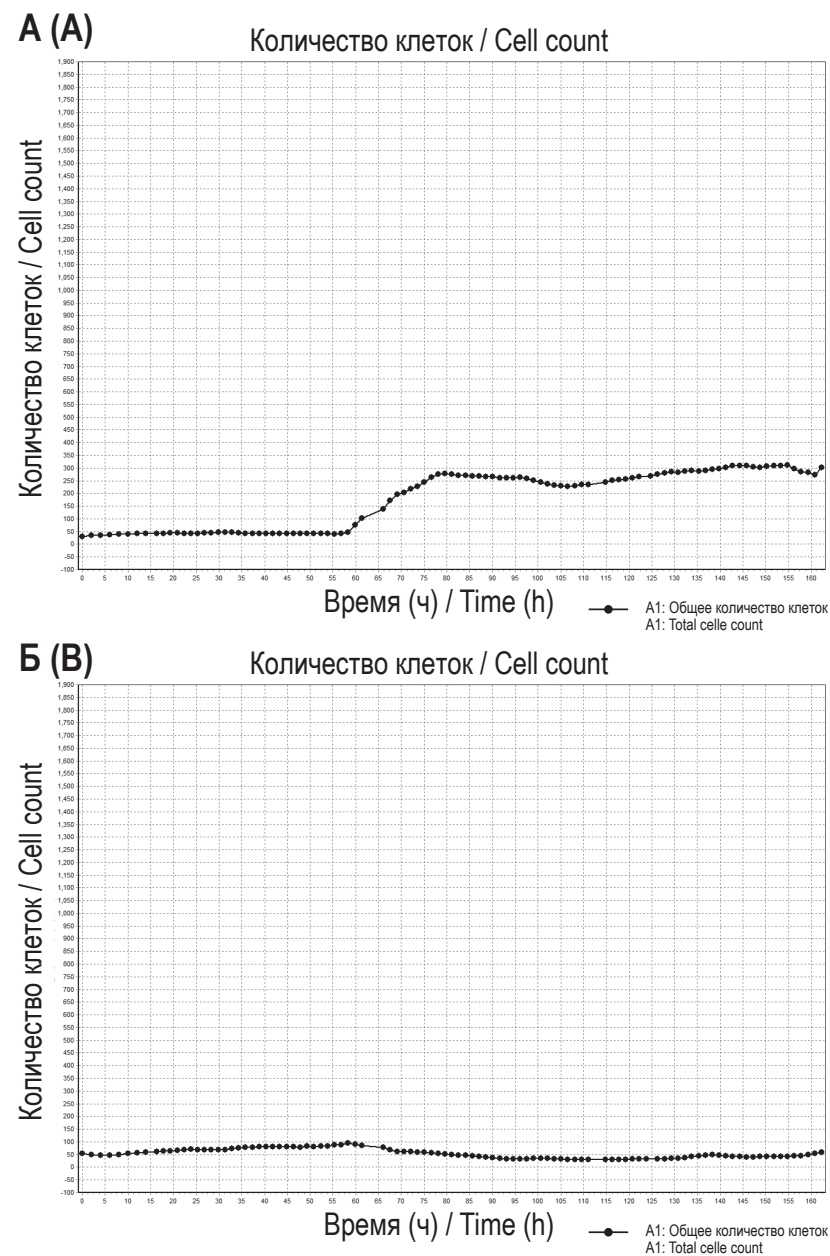

ние 14 суток) культивирование Jurkat Т-клеток в ППС с использованием RPMI 1640 в качестве основы приводило к статистически значимому снижению концентраций 17 из 27 тестируемых цитокинов, хемокинов и факторов роста в сравнении с соответствующими значениями в 2-дневной культуре лейкозных клеток. Секреция многих биомолекул падала до нулевых значений (IL-1 $\beta$, IL-1 ra, IL-2, IL-5, IL-6, IL-13, IL-15, IL-17, IP-10, MIP-1 $\beta$ ).

В свою очередь, при 14-дневном культивировании в ППС на основе $\alpha$ МЕМ секреторная активность клеток значительно превышала таковую для питательной среды на основе RPMI 1640. Содержание в супернатантах всех тестируемых факторов (за исключением IL-5, IL-9, IL-15 и IL-17) было выше в 10-100 раз с сравнении с соответствующими результатами в RPMI 1640. Так, например, уровень VEGF оказался выше в 348 раз (табл. 1).

Активация секреции биомолекул в ППС на основе $\alpha$ МЕМ сопровождалось 5-кратным приростом клеточной биомассы к 7-м суткам эксперимента (рис. 1) и достоверной разницей (более чем на $13 \%$ ) в относительном числе жизнеспособных клеток к 14-м суткам наблюдения (табл. 2). В среде $\alpha$ МЕМ значительно сокращалось (на

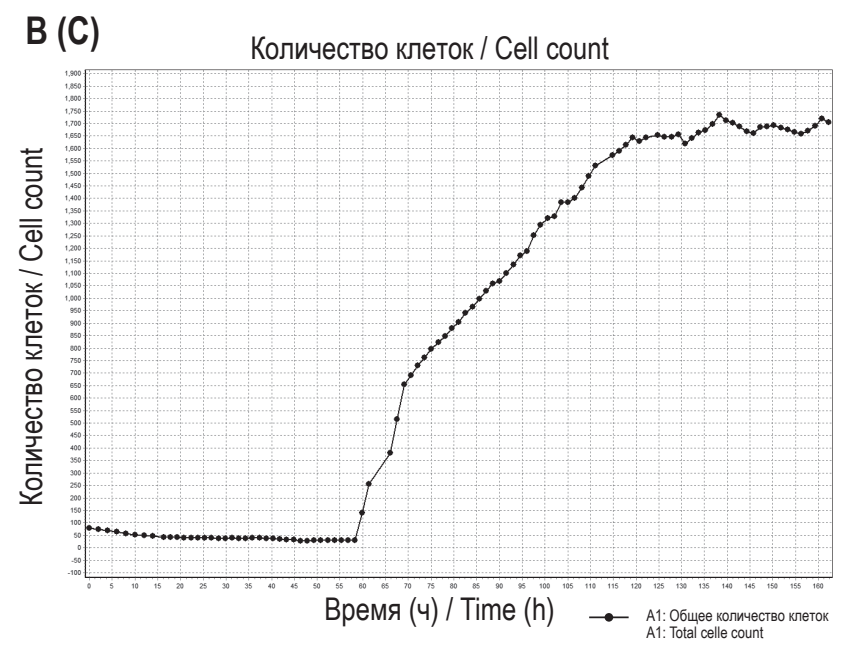

Рисунок 1. Характерная динамика аккумуляции Jurkat T-клеток в одном из шести полей Cell-IQ визуализации Примечание. А, Б - клеточная культура в среде на основе RPMI 1640. B - на основе $\alpha$ MEM.

Figure 1. Individual dynamics of Jurkat $\mathrm{T}$ cell accumulation in one of the six visualization fields

Note. A, B, cell culture on a base of RPMI 1640 medium. C, on a base of $\alpha$ MEM medium. 
ТАБЛИЦА 1. СЕКРЕТОРНАЯ АКТИВНОСТЬ (ПГ/МЛ) ЈURКАТ Т-КЛЕТОК ПОСЛЕ 2-Х И 14-Х СУТОК КУЛЬТИВИРОВАНИЯ, $\operatorname{Me}\left(Q_{0,25} Q_{0,75}\right)$

TABLE 1. SECRETORY ACTIVITY (pg/ml) OF JURKAT T-CELLS AFTER 2 OR 14 DAYS OF CULTURE, Me $\left(Q_{0.25}-Q_{0.75}\right)$

\begin{tabular}{|c|c|c|c|c|c|c|c|c|c|c|c|c|c|c|}
\hline \multicolumn{15}{|c|}{$\begin{array}{l}\text { Воспалительные цитокины } \\
\text { Inflammation cytokines }\end{array}$} \\
\hline IL-1 $\beta$ & IL-1ra & IL-2 & IL-4 & IL-5 & IL-6 & IL-7 & IL-9 & IL-10 & $\begin{array}{l}\text { IL-12 } \\
(p 70)\end{array}$ & IL-13 & IL-15 & IL-17 & $\mathrm{TNF} \alpha$ & IFN $\gamma$ \\
\hline \multicolumn{15}{|c|}{2 суток в RPMI 1640 / 2 days in RPMI 1640, $n=4$} \\
\hline $\begin{array}{c}0,46 \\
(0,43- \\
0,63)\end{array}$ & $\begin{array}{c}7,65 \\
(3,23- \\
8,65)\end{array}$ & $\begin{array}{c}1,90 \\
(0,92- \\
2,11)\end{array}$ & $\begin{array}{l}0,21 \\
(0,0- \\
0,3)\end{array}$ & $\begin{array}{c}2,87 \\
(1,25- \\
3,22)\end{array}$ & $\begin{array}{c}2,39 \\
(2,03- \\
3,12)\end{array}$ & $\begin{array}{c}0 \\
(0-0)\end{array}$ & $\begin{array}{c}1,72 \\
(0,99- \\
1,98)\end{array}$ & $\begin{array}{c}9,90 \\
(9,63- \\
10,46)\end{array}$ & $\begin{array}{c}4,89 \\
(3,45- \\
5,52)\end{array}$ & $\begin{array}{c}1,48 \\
(1,26- \\
2,12)\end{array}$ & $\begin{array}{c}5,49 \\
(4,38- \\
6,55)\end{array}$ & $\begin{array}{c}2,21 \\
(1,09- \\
3,20)\end{array}$ & $\begin{array}{c}6,09 \\
(3,29- \\
10,23)\end{array}$ & $\begin{array}{c}0 \\
(0-0)\end{array}$ \\
\hline \multicolumn{15}{|c|}{14 суток в RPMI $1640 / 14$ days in RPMI, $n=4, p_{T}<0,05$} \\
\hline $\begin{array}{c}0^{*} \\
(0,00- \\
0,04)\end{array}$ & $\begin{array}{c}0 \\
(0,00- \\
5,67)\end{array}$ & $\begin{array}{c}0^{*} \\
(0,00- \\
0,24)\end{array}$ & $\begin{array}{c}0,06 \\
(0,00- \\
0,18)\end{array}$ & $\begin{array}{c}0^{*} \\
(0-0)\end{array}$ & $\begin{array}{c}0^{*} \\
(0,00- \\
0,15)\end{array}$ & $\begin{array}{c}0 \\
(0,00- \\
0,23)\end{array}$ & $\begin{array}{c}0,38 \\
(0,17- \\
3,26)\end{array}$ & $\begin{array}{c}0,63^{*} \\
(0,07- \\
2,71)\end{array}$ & $\begin{array}{c}3,91 \\
(1,62- \\
4,94)\end{array}$ & $\begin{array}{c}0^{*} \\
(0,00- \\
0,27)\end{array}$ & $\begin{array}{c}0^{*} \\
(0-0)\end{array}$ & $\begin{array}{c}0^{*} \\
(0,00- \\
0,48)\end{array}$ & $\begin{array}{c}1,72^{*} \\
(0,68- \\
2,41)\end{array}$ & $\begin{array}{c}0 \\
(0,00- \\
6,11)\end{array}$ \\
\hline \multicolumn{15}{|c|}{14 суток в $\alpha$ MEM / 14 days in $\alpha M E M, n=5, p_{T}<0,05$} \\
\hline $\begin{array}{c}0,37^{\#} \\
(0,36- \\
0,37)\end{array}$ & $\begin{array}{c}40,08^{\#} \\
(36,56- \\
45,06)\end{array}$ & $\begin{array}{c}0,92^{\#} \\
(0,68- \\
1,37)\end{array}$ & $\begin{array}{c}1,0^{\#} \\
(0,67- \\
1,09)\end{array}$ & $\begin{array}{c}0 \\
(0,00- \\
0,54)\end{array}$ & $\begin{array}{c}487,0^{\#} \\
(479,18- \\
491,01)\end{array}$ & $\begin{array}{c}1,94^{\#} \\
(1,81- \\
3,03)\end{array}$ & $\begin{array}{c}3,88 \\
(3,31- \\
4,32)\end{array}$ & $\begin{array}{c}19,58^{\#} \\
(19,29- \\
20,39)\end{array}$ & $\begin{array}{c}88,52^{\#} \\
(88,45- \\
89,48)\end{array}$ & $\begin{array}{c}2,44^{\#} \\
(1,94- \\
2,57)\end{array}$ & $\begin{array}{c}0 \\
(0-0)\end{array}$ & $\begin{array}{c}1,20 \\
(0,43- \\
2,52)\end{array}$ & $\begin{array}{l}9,99^{\#} \\
(9,03- \\
12,81)\end{array}$ & $\begin{array}{c}51,16^{\#} \\
(29,56- \\
53,73)\end{array}$ \\
\hline
\end{tabular}

\begin{tabular}{|c|c|c|c|c|c|c|c|c|c|c|c|}
\hline \multicolumn{3}{|c|}{$\begin{array}{c}\text { Ангиогенные молекулы } \\
\text { Angiogenic molecules }\end{array}$} & \multicolumn{2}{|c|}{$\begin{array}{c}\text { Гемопоэтические } \\
\text { факторы роста } \\
\text { Hemopoietic growth } \\
\text { factors }\end{array}$} & \multicolumn{7}{|c|}{$\begin{array}{l}\text { Хемокины } \\
\text { Chemokines }\end{array}$} \\
\hline bFGF & VEGF & $\begin{array}{l}\text { PDGF- } \\
\text { BB }\end{array}$ & G-CSF & GM-CSF & $\begin{array}{c}\text { IL-8 } \\
\text { (CXCL8) }\end{array}$ & $\begin{array}{l}\text { Eotaxin } \\
(C C L 11)\end{array}$ & $\begin{array}{c}\text { IP-10 } \\
(\mathrm{CXCL10})\end{array}$ & $\begin{array}{l}\text { MCP-1 } \\
\text { (CCL2) }\end{array}$ & $\begin{array}{l}\text { MIP-1 } \alpha \\
\text { (CCL3) }\end{array}$ & $\begin{array}{l}\text { MIP-1 } \beta \\
(C C L 4)\end{array}$ & $\begin{array}{l}\text { RANTES } \\
\text { (CCL5) }\end{array}$ \\
\hline \multicolumn{12}{|c|}{2 суток в RPMI 1640 / 2 days in RPMI 1640, $n=4$} \\
\hline $\begin{array}{c}6,54 \\
(6,24- \\
10,32)\end{array}$ & $\begin{array}{c}94,43 \\
(81,59- \\
108,89)\end{array}$ & $\begin{array}{c}0 \\
(0-0)\end{array}$ & $\begin{array}{c}0 \\
(0-0)\end{array}$ & $\begin{array}{c}93,21 \\
(86,56- \\
95,64)\end{array}$ & $\begin{array}{c}3,22 \\
(3,20-6,12)\end{array}$ & $\begin{array}{c}1,03 \\
(0,00- \\
2,09)\end{array}$ & $\begin{array}{c}5,22 \\
(4,20-5,22)\end{array}$ & $\begin{array}{c}6,49 \\
(5,16- \\
7,13)\end{array}$ & $\begin{array}{c}0,43 \\
(0,43- \\
1,07)\end{array}$ & $\begin{array}{c}2,34 \\
(1,25- \\
2,50)\end{array}$ & $\begin{array}{c}3,2 \\
(2,89- \\
5,34)\end{array}$ \\
\hline \multicolumn{12}{|c|}{14 суток в RPMI 1640 / 14 days in RPMI 1640, $\mathrm{n}=4, \mathrm{p}_{\mathrm{T}}<0,05$} \\
\hline $\begin{array}{c}1,86 \\
(0,00- \\
8,96)\end{array}$ & $\begin{array}{l}4,98^{*} \\
(0,00- \\
40,35)\end{array}$ & $\begin{array}{c}0,19 \\
(0,00- \\
0,53)\end{array}$ & $\begin{array}{c}0,59 \\
(0,00- \\
1,92)\end{array}$ & $\begin{array}{l}11,64^{*} \\
(0,70- \\
28,04)\end{array}$ & $\begin{array}{c}0,96^{*} \\
(0,18-3,07)\end{array}$ & $\begin{array}{c}1,22 \\
(0,53- \\
1,79)\end{array}$ & $\begin{array}{c}0^{*} \\
(0,00-3,18)\end{array}$ & $\begin{array}{l}0,91^{*} \\
(0,00- \\
3,16)\end{array}$ & $\begin{array}{c}0,06^{*} \\
(0,00- \\
0,14)\end{array}$ & $\begin{array}{c}0^{*} \\
(0,00- \\
0,26)\end{array}$ & $\begin{array}{c}0,02^{*} \\
(0,00- \\
0,50)\end{array}$ \\
\hline \multicolumn{12}{|c|}{14 суток в $\alpha$ MEM / 14 days in $\alpha M E M, n=5, p_{T}<0,05$} \\
\hline $\begin{array}{c}14,48^{\#} \\
(14,47- \\
17,95)\end{array}$ & $\begin{array}{c}1735,28^{\#} \\
(1707,46- \\
1767,77)\end{array}$ & $\begin{array}{c}2,16^{\#} \\
(2,14- \\
3,83)\end{array}$ & $\begin{array}{c}43,77^{\#} \\
(39,28- \\
45,67)\end{array}$ & $\begin{array}{l}58,94^{\#} \\
(55,33- \\
59,20)\end{array}$ & $\begin{array}{l}47,69^{\#} \\
(47,57- \\
47,70)\end{array}$ & $\begin{array}{l}10,49^{\#} \\
(9,97- \\
10,79)\end{array}$ & $\begin{array}{l}21,27^{\#} \\
(19,49- \\
22,53)\end{array}$ & $\begin{array}{c}19,55^{\#} \\
(18,57- \\
20,02)\end{array}$ & $\begin{array}{c}0,29 \# \\
(0,25- \\
0,39)\end{array}$ & $\begin{array}{c}4,58^{\#} \\
(4,58- \\
4,63)\end{array}$ & $\begin{array}{c}1,32^{\#} \\
(1,26- \\
1,52)\end{array}$ \\
\hline
\end{tabular}

Примечание. * - статистические различия $($ р < 0,05) с показателями в 2-дневной, \# - в 14-дневной культурах согласно критерию Манна-Уитни; $\mathbf{p}_{\mathrm{T}}$ - различия согласно Т-критерию Вилкоксона; $\mathbf{n}$ - число исследованных лунок. Каждое измерение в лунках было выполнено трижды.

Note. * , statistical differences $(p<0,05)$ with results in 2-day, ${ }^{\#}$, in 14-day cultures according to the Mann-Whitney test; $p_{T}$, according to the Wilcoxon test; $n$, the number of wells studied; each measurement in wells was done in triplicate. 
ТАБЛИЦА 2. ЖИЗНЕСПОСОБНОСТЬ ЈURКАТ Т-КЛЕТОК И CEll-IQ МОНИТОРИНГ ИЗМЕНЕНИЯ ИХ ЧИСЛА В КУЛЬТУРАХ С РАЗЛИЧНЫМИ ПИТАТЕЛЬНЫМИ СРЕДАМИ, Ме $\left(Q_{0,25}-Q_{0,75}\right), X \pm S D$

TABLE 2. VIABILITY OF JURKAT T-CELLS AND Cell-IQ MONITORING OF THEIR NUMBER CHANGE IN CULTURES WITH DIFFERENT NUTRIENT MEDIA, Me $\left(Q_{0.25}-Q_{0.75}\right), X \pm S D$

\begin{tabular}{|c|c|c|c|c|c|c|}
\hline \multirow[b]{2}{*}{$\begin{array}{c}\text { Тип } \\
\text { питательной } \\
\text { среды в } \\
\text { клеточной } \\
\text { культуре } \\
\text { Type of nutrient } \\
\text { medium } \\
\text { n=3 }\end{array}$} & \multirow[b]{2}{*}{$\begin{array}{c}\text { Живые } \\
\text { клетки } \\
\text { Live cells }\end{array}$} & \multirow[b]{2}{*}{$\begin{array}{c}\text { Клетки в } \\
\text { состоянии } \\
\text { апоптоза } \\
\text { Apoptotic } \\
\text { cells }\end{array}$} & \multirow[b]{2}{*}{$\begin{array}{c}\text { Клетки в } \\
\text { состоянии } \\
\text { некроза } \\
\text { Necrotic } \\
\text { cells }\end{array}$} & \multicolumn{3}{|c|}{$\begin{array}{c}\text { 7-суточный Cell-IQ мониторинг } \\
\text { 7-day Cell-IQ monitoring }\end{array}$} \\
\hline & & & & $\begin{array}{c}\text { Прирост } \\
\text { числа клеток } \\
\text { в каждой } \\
\text { области } \\
\text { визуализации } \\
\text { к концу } \\
\text { наблюдений } \\
\text { Growth of cell } \\
\text { count in each } \\
\text { visualization } \\
\text { point by the end } \\
\text { of observation } \\
\mathrm{n}_{1}=18\end{array}$ & $\begin{array}{c}\text { Время (ч) } \\
\text { достижения } \\
\text { максимальной } \\
\text { концентрации } \\
\text { клеток в } \\
\text { каждой области } \\
\text { визуализации } \\
\text { Time (h) of getting } \\
\text { the maximal cell } \\
\text { concentration in } \\
\text { each visualization } \\
\text { point } \\
\mathrm{n}_{1}=18\end{array}$ & $\begin{array}{c}\text { Лаг-период (ч) } \\
\text { до подъема } \\
\text { числа клеток } \\
\text { в поле зрения } \\
\text { Lag-period } \\
\text { (h) before } \\
\text { cell count } \\
\text { augmentation in } \\
\text { visual field } \\
\mathrm{n}_{1}=18\end{array}$ \\
\hline \multicolumn{4}{|c|}{$\begin{array}{c}\text { Доля клеток через } 2 \text { суток, \% } \\
\text { Cell proportion after } 2 \text { days, \% }\end{array}$} & - & - & - \\
\hline $\begin{array}{l}\text { На основе } \\
\text { RPMI } 1640 \\
\text { On a base of } \\
\text { RPMI } 1640\end{array}$ & $\begin{array}{c}91,1 \\
(89,0-91,3)\end{array}$ & $\begin{array}{c}2,8 \\
(3,5-4,8)\end{array}$ & $\begin{array}{c}6,1 \\
(4,9-7,5)\end{array}$ & - & - & - \\
\hline \multicolumn{4}{|c|}{$\begin{array}{c}\text { Доля клеток через } 14 \text { суток, \% } \\
\text { Cell proportion after } 14 \text { days, \% }\end{array}$} & - & - & - \\
\hline $\begin{array}{l}\text { На основе } \\
\text { RPMI } 1640 \\
\text { On a base of } \\
\text { RPMI } 1640\end{array}$ & $\begin{array}{c}79,3^{*} \\
(78,2-88,8) \\
<0,05\end{array}$ & $\begin{array}{c}3,2 \\
(3,0-7,4)\end{array}$ & $\begin{array}{c}13,4^{*} \\
(8,2-18,7) \\
<0,05\end{array}$ & $\begin{array}{c}280 \\
(0-1140)\end{array}$ & $\begin{array}{c}168 \\
(100-168)\end{array}$ & $81,9 \pm 46,5$ \\
\hline $\begin{array}{l}\text { На основе } \\
\alpha \text { MEM } \\
\text { On a base of } \\
\alpha \text { MEM }\end{array}$ & $\begin{array}{c}92,9^{\#} \\
(92,5-93,8) \\
<0,05\end{array}$ & $\begin{array}{c}2,3^{\#} \\
(2,1-2,5) \\
<0,05\end{array}$ & $\begin{array}{c}4,6^{\#} \\
(4,2-5,3) \\
<0,01\end{array}$ & $\begin{array}{c}1412^{\#} \\
(650-1575) \\
<0,01\end{array}$ & $\begin{array}{c}164 \\
(140-168)\end{array}$ & $\begin{array}{l}55,8 \pm 9,2^{\#} \\
\quad<0,04\end{array}$ \\
\hline
\end{tabular}

Примечание. См. примечание к таблице 1. $\mathrm{n}$ - число исследованных лунок; каждое измерение в лунках было выполнено трижды; $\mathrm{n}_{1}$ - количество полей визуализации во всех лунках.

Note. As for Table 1. $\mathrm{n}$, the number of wells studied; each measurement in wells was done in triplicate; $\mathrm{n}_{1}$, the number of visualization points in all the wells.

$32 \%, \mathrm{p}<0,04)$ время адаптации клеток к условиям культивирования (лаг-период) перед их активной пролиферацией (табл. 2). При этом число Jurkat Т-клеток в некоторых полях зрения при культивировании в RPMI 1640 (рис. 1Б) не менялось в течение всего срока Cell-IQ непрерывного мониторинга. В $\alpha \mathrm{MEM}$ многоклеточные кластеры (рис. 2, см. 3-ю стр. обложки) начинали формироваться гораздо раньше (в среднем с 6-го часа от начала культивирования), чем в RPMI 1640 (с 17-го часа; $\mathrm{p}<0,02)$, что свидетельствует в пользу повышенной межклеточной адгезии.

Полученные данные свидетельствуют в пользу предпочтительности состава питательной среды $\alpha \mathrm{MEM} \mathrm{для} \mathrm{жизнедеятельности} \mathrm{активно} \mathrm{проли-}$ ферирующих и секретирующих Jurkat Т-клеток при их длительном (7-14 суток) культивировании.

\section{Обсуждение}

Химический состав культуральных сред в определенной степени воспроизводит необхо- 
димые метаболиты для поддержания роста определенных линий клеток вне организма. Рекомендуемой средой для культивирования Jurkat T-клеток является RPMI 1640 [1]. Она прописана в паспорте клеточной линии и применяется в большинстве исследований $[13,24]$. В то же время редкие эксперименты с культурой клеток Jurkat проводятся с использованием сред на основе МЕМ в частности [8].

Однако наши результаты (табл. 1-2, рис. 1) показали, что среда $\alpha$ МЕМ в составе ППС является более подходящей по своим свойствам для поддержания in vitro жизнеспособности, секреторной активности и клеточной биомассы культуры Jurkat Т-клеток в интервале 7-14 суток. Мы ожидали, что присутствие ЭТС должно в значительной степени нивелировать влияние базовых культуральных сред, однако этого не произошло. Как следствие, были проанализированы основные различия в их химическом составе (табл. 3) и механизмы возможного влияния на поведение лейкозных клеток.

Первое, что обращает на себя внимание, это более богатый состав аминокислот вообще и их незаменимых форм (за исключением триптофана) в составе среды $\alpha$ МЕМ (табл. 3). Недостаток нутриентов, прежде всего незаменимых аминокислот, вызывает клеточное голодание Jurkat Т-клеток и запускает их аутофагию, что вызывает снижение числа клеток в культуре, а также их функциональную активность (табл. 1-2) [11].

С другой стороны, A. Kuban-Jankowska и coавт. (2011) также показали, что МЕМ-среда эффективнее для краткосрочного (до 3 ч) культивирования Jurkat T-клеток в сравнении с RPMI 1640 [18]. Согласно данным авторов, RPMI 1640 в три раза сильнее (в сравнении с МЕМ) подавляла активность CD45 молекулы (общий лейкоцитарный антиген; тирозиновая протеинфосфатаза) на лейкозных клетках in vitro. При этом ингибиция CD45-фосфатазной активности приводит к аресту клеточного цикла и апоптозу Jurkat Т-клеток [23].

В условиях ex vivo высокие концентрации кислорода приводят в культуральных средах, включая RPMI 1640 и MEM, к спонтанному образованию активных форм кислорода (АФК) [19]. Окислительный стресс вызывает трансформацию химических компонентов синтетических сред с формированием перекиси водорода, которая, в свою очередь, приводит к инактивации CD45 [18]. Основными молекулами-мишенями, участвующими в генерации/трансформации АФК, являются:
1) восстановленный глютатион (присутствует в RPMI 1640, табл. 3);

2) серосодержащие аминокислоты цистеин (присутствует в $\alpha \mathrm{MEM,} \mathrm{табл.} 3$ ) и метионин;

3) аминокислоты тирозин, фенилаланин, пролин, гистидин и аргинин, концентрация которых, в основном, преобладает в $\alpha$ МЕМ (табл. 3) [2, 18].

При этом работа с культурами (смена среды каждые 3-4 дня) и Cell-IQ непрерывный мониторинг (каждые 1,5 ч в течение 7 суток) способствуют периодическому воздействию света на клеточные культуры. Многие аминокислоты являются фотореактивными, например, триптофан, тирозин и гистидин продуцируют на свету супероксид-анион. При 3-часовом освещении в условиях ламинарного шкафа (примерно 800 люкс) отмечалась дополнительная (на 22\%) супрессия CD45 на Jurkat T-клетках, культивируемых в RPMI 1640 [18].

Из представленных данных возникает предположение о большей реактивности компонентов среды $\alpha \mathrm{MEM} \mathrm{в} \mathrm{окислительных} \mathrm{процессах.} \mathrm{Одна-}$ ко для динамики развития окислительного стресса имеют значение антиоксиданты. Так, следует отметить наличие в $\alpha$ MEM, но не в RPMI 1640, пировиноградной кислоты, которая способствует сохранению жизнеспособности и CD45 активности в Jurkat T-клетках, а также аскорбиновой кислоты как известного антиоксиданта $[2,18]$.

Далее следует отметить ускоренную почти в 3 раза кластеризацию (рис. 2) лейкозных Т-лимфобластов линии Jurkat в ППС на основе $\alpha$ MEM, что может быть связано с более высоким уровнем в ней ионов кальция (табл. 3). В свою очередь, клеточная адгезия уменьшает площадь поверхности мембран, доступных для АФК, генерируемых компонентами питательных сред в межклеточной жидкости.

Кроме того, противовоспалительные цитокины IL-4 и IL-13 тормозят клеточную продукцию АФК [6, 9]. Цитокиновые механизмы подавления окислительного стресса (IL-4 и IL-13) и активации пролиферации/жизнеспособности Jurkat T-клеток (IL-2, IL-4, IL-6) могут работать в ППС на основе $\alpha$ MEM, в которой клеточная культура проявляла высокую секреторную способность на протяжении 14 суток (табл. 1) [17].

\section{Заключение}

Правильный выбор питательных сред для культивирования различных видов клеток в разнообразных приложениях является одним из важнейших аспектов современных биотехноло- 


\section{ТАБЛИЦА З. ОСНОВНЫЕ РАЗЛИЧИЯ В ХИМИЧЕСКОМ СОСТАВЕ ПИТАТЕЛЬНЫХ СРЕД ДЛЯ КУЛЬТИВИРОВАНИЯ} JURKAT T-КЛЕTOK

TABLE 3. MAIN DIFFERENCES IN CHEMICAL COMPOSITION OF NUTRIENT MEDIA FOR JURKAT T-CELL CULTURE

\begin{tabular}{|c|c|c|}
\hline \multirow{2}{*}{$\begin{array}{l}\text { Компоненты } \\
\text { Compounds }\end{array}$} & $\begin{array}{l}\text { среда RPMI } 1640 \text { ( } 31870) \\
\text { RPMI } 1640 \text { medium }\end{array}$ & $\begin{array}{c}\text { среда } \alpha \text { MEM (M4526) } \\
\alpha M E M \text { medium }\end{array}$ \\
\hline & $\begin{array}{c}\mathbf{r} / \pi \\
\mathrm{g} / \mathrm{l}\end{array}$ & $\begin{array}{l}/ ת \\
\mathrm{~g} / \mathrm{l}\end{array}$ \\
\hline \multicolumn{3}{|c|}{$\begin{array}{c}\text { Неорганические соли } \\
\text { Inorganic salts }\end{array}$} \\
\hline $\begin{array}{l}\text { Соли кальция } \\
\text { Calcium salts }\end{array}$ & 0,1 & 0,2 \\
\hline \multicolumn{3}{|c|}{$\begin{array}{l}\text { Аминокислоты } \\
\text { Amino acids }\end{array}$} \\
\hline $\begin{array}{l}\text { L-aргинин (условно незаменимая) } \\
\text { L-arginin (conditionally essential) }\end{array}$ & 0,2 & 0,126 \\
\hline $\begin{array}{l}\text { L-acпартат } \\
\text { L-aspartate }\end{array}$ & 0,02 & 0,03 \\
\hline $\begin{array}{l}\text { L-цистеин } \\
\text { L-cysteine }\end{array}$ & - & 0,1 \\
\hline $\begin{array}{l}\text { L-гистидин (условно незаменимая) } \\
\text { L-histidine (conditionally essential) }\end{array}$ & 0,015 & 0,042 \\
\hline $\begin{array}{l}\text { L- гидроксипролин } \\
\text { L-hydroxyproline }\end{array}$ & 0,02 & - \\
\hline $\begin{array}{l}\text { Глицин } \\
\text { Glycine }\end{array}$ & 0,01 & 0,05 \\
\hline $\begin{array}{l}\text { L-глутаминовая кислота } \\
\text { L-glutamic acid }\end{array}$ & 0,02 & 0,075 \\
\hline $\begin{array}{l}\text { L-лизингидрохлорид (незаменимая) } \\
\text { L-lysinehydrochloride (essential) }\end{array}$ & 0,04 & 0,0725 \\
\hline $\begin{array}{l}\text { L-фениилаланин (незаменимая) } \\
\text { L-phenylalanine (essential) }\end{array}$ & 0,015 & 0,032 \\
\hline $\begin{array}{l}\text { L-пролин } \\
\text { L-proline }\end{array}$ & 0,02 & 0,04 \\
\hline $\begin{array}{l}\text { L-треонин (незаменимая) } \\
\text { L-threonine (essential) }\end{array}$ & 0,02 & 0,048 \\
\hline $\begin{array}{l}\text { L-триптофран (незаменимая) } \\
\text { L-tryptophan (essential) }\end{array}$ & 0,05 & 0,01 \\
\hline $\begin{array}{l}\text { L-тирозин } \\
\text { L-tyrosine }\end{array}$ & 0,02 & 0,0519 \\
\hline $\begin{array}{l}\text { L-валин (незаменимая) } \\
\text { L-valine (essential) }\end{array}$ & 0,02 & 0,046 \\
\hline \multicolumn{3}{|c|}{$\begin{array}{l}\text { Витамины } \\
\text { Vitamins }\end{array}$} \\
\hline $\begin{array}{l}\text { L-аскорбиновая кислота } \\
\text { L-Ascorbic Acid }\end{array}$ & - & 0,05 \\
\hline $\begin{array}{l}\text { Биотин } \\
\text { Biotin }\end{array}$ & 0,0002 & 0,0001 \\
\hline $\begin{array}{l}\text { Холинхлорид } \\
\text { Cholinechloride }\end{array}$ & 0,003 & 0,001 \\
\hline $\begin{array}{l}\text { Кальция D-пантотенат } \\
\text { D-Calciumpantothenate }\end{array}$ & 0,00025 & 0,001 \\
\hline
\end{tabular}


Таблица 3 (окончание)

Table 3 (continued)

\begin{tabular}{|c|c|c|}
\hline \multirow{2}{*}{$\begin{array}{l}\text { Компоненты } \\
\text { Compounds }\end{array}$} & $\begin{array}{l}\text { среда RPMI } 1640 \text { (31870) } \\
\text { RPMI } 1640 \text { medium }\end{array}$ & $\begin{array}{c}\text { среда } \alpha \text { MEM (M4526) } \\
\alpha \text { MEM medium }\end{array}$ \\
\hline & $\begin{array}{c}\mathrm{r} / \boldsymbol{л} \\
\mathrm{g} / \mathrm{l}\end{array}$ & $\begin{array}{l}\mathrm{r} / \boldsymbol{\pi} \\
\mathrm{g} / \mathrm{l}\end{array}$ \\
\hline $\begin{array}{l}\text { Липоевая кислота } \\
\text { Lipoic Acid }\end{array}$ & - & 0,0002 \\
\hline $\begin{array}{l}\text { Пара-аминобензойная кислота } \\
\text { Para-Aminobenzoic Acid }\end{array}$ & 0,001 & - \\
\hline $\begin{array}{l}\text { Рибофлавин } \\
\text { Riboflavin }\end{array}$ & 0,0002 & 0,0001 \\
\hline $\begin{array}{l}\text { Витамин } \mathrm{B}_{12} \\
\text { Vitamin } \mathrm{B}_{12}\end{array}$ & 0,000005 & 0,00136 \\
\hline $\begin{array}{l}\text { Инозитол } \\
\text { Inositol }\end{array}$ & 0,0035 & 0,002 \\
\hline \multicolumn{3}{|c|}{$\begin{array}{c}\text { Другие компоненты } \\
\text { Other compounds }\end{array}$} \\
\hline $\begin{array}{l}\text { D-глюкоза } \\
\text { D-glucose }\end{array}$ & 2,0 & 1,0 \\
\hline $\begin{array}{l}\text { Глютатион восстановленный } \\
\text { Glutathione (reduced) }\end{array}$ & 0,001 & - \\
\hline $\begin{array}{l}\text { Пировиноградная кислота } \\
\text { Pyruvic Acid }\end{array}$ & - & 0,11 \\
\hline
\end{tabular}

гий. Среда RPMI 1640 рекомендуется для использования в in vitro манипуляциях с лейкозными линиями Т-лимфоцитов, включая Jurkat Т-клетки, которые, в свою очередь, широко применяются в различных исследованиях ex vivo [18]. Полученные нами данные показывают малую пригодность химического состава данной питательной среды для изучения поведения Jurkat Т-клеток в долгосрочных экспериментах. В связи с этим, тестирование in vitro медицинских изделий, пред- назначенных для долговременного контакта с организмом, в том числе у онкологических больных, на лейкозной линии Jurkat Т-клеток в среде RPMI 1640 могут обусловить ошибочный прогноз их биосовместимости и потенциальной противоопухолевой активности. Среда $\alpha \mathrm{MEM} \mathrm{является}$ более подходящей по своим свойствам для поддержания in vitro жизнеспособности, секреторной активности и клеточной биомассы культуры Jurkat Т-клеток в интервале 7-14 суток.

\section{Список литературы / References}

1. Мамаева С.Е. Атлас хромосом постоянных клеточных линий человека и животных. М.: Научный мир, 2002. 236 с. [Mamaeva S.E. Atlas of chromosomes of permanent cell lines of humans and animals]. Moscow: Nauchnyy mir, 2002. 236 p.

2. Меньщикова Е.Б., Ланкин В.З., Зенков Н.К., Бондарь И.А., Круговых Н.Ф., Труфакин В.А. Окислительный стресс. Прооксиданты и антиоксиданты. М.: Фирма «Слово», 2006. 556 с. [Menshchikova E.B., Lankin V.Z., Zenkov N.K., Bondar I.A., Krugovykh N.F., Trufakin V.A. Oxidative stress. Procosidants and antioxidants]. Moscow: Firma «Slovo», 2006. 556 p.

3. Симбирцев А.С. Цитокины в патогенезе и лечении заболеваний человека. СПб: Фолиант, 2018. 512 c. [Simbirtsev A.S. Cytokines in the pathogenesis and treatment of diseases person]. St. Petersburg: Foliant, 2018. 512 p.

4. Черезова А.Л., Негуляев Ю.А., Зенин В.В., Семенова С.Б. рН среды регулирует вход кальция в Т-клетки Jurkat. Цитология, 2017. Т. 59, № 9. С. 595-600. [Cherezova A.L., Negulyaev Yu.A., Zenin V.V., Semenova S.B. Extracellular $\mathrm{pH}$ regulates calcium influx in Jurkat T-cells. Tsitologiya = Cytology, 2017, Vol. 59, no. 9, pp. 595-600. (In Russ.)] 
5. Abraham R.T., Weiss A. Jurkat T cells and development of the T-cell receptor paradigm. Nat. Rev. Immunol., 2004, Vol. 4, pp. 301-308.

6. Al-Ramadi B.K., Meissler J.J., Huang D., Eisenstein T.K. Immunosuppression induced by nitrci oxide and its inhibition by interleukin-4. Eur. J. Immunol., 1992, Vol. 22, no. 9, pp. 2249-2254.

7. Au A., Ha J., Hernandez M., Polotsky A., Hungerford D.S., Frondoza C.G. Nickel and vanadium metal ions induce apoptosis of T-lymphocyte Jurkat cells. J. Biomed. Mater. Res., 2006, Vol. 79, pp. 512-521.

8. Audiffred J.F., De Leo S.E., Brown P.K., Hale-Donze H., Monroe W.T. Characterization and applications of serum-free induced adhesion in Jurkat suspension cells. Biotechnol. Bioeng., 2010, Vol. 106, no. 5, pp. $784-793$.

9. Bogdan C., Thuring H., Dlaska M., Rollinghoff M., Weiss G. Mechanism of suppression of macrophage nitric oxide release by IL-13: influence of the macrophage population. J. Immunol., 1997, Vol. 159, no. 9, pp. 4506-4513.

10. Caicedo M., Jacobs J.J., Reddy A., Hallab N.J. Analysis of metal ion-induced DNA damage, apoptosis, and necrosis in human (Jurkat) T-cells demonstrates $\mathrm{Ni} 2+$ and $\mathrm{V} 3+$ are more toxic than other metals: $\mathrm{Al} 3^{+}, \mathrm{Be} 2^{+}, \mathrm{Co}^{+}$, $\mathrm{Cr}^{+}, \mathrm{Cu} 2^{+}, \mathrm{Fe}^{+}, \mathrm{Mo5}^{+}, \mathrm{Nb}^{+}, \mathrm{Zr2}{ }^{+}$. J. Biomed. Mater. Res., 2008, Vol. 86, no. 4, pp. 905-913.

11. Chan L.L.-Y., Lai N., Shen D., Wilkinson A.R., Patton W., Chan E., Kuksin D., Lin B., Qui J. A rapid method for detecting autophagy activity in live cells using cellometer image cytometry. In: Autophagy: Cancer, Other Pathologies, Inflammation, Immunity, Infection, and Aging. Vol. 10. Elsevier: Academic Press, 2016, pp. 169-183.

12. Chen X., Su J., Chang J., Kanekura T., Li J., Kuang Y.H., Peng S., Yang F., Lu H., Zhang J.L. Inhibition of CD147 gene expression via RNA interference reduces tumor cell proliferation, activation, adhesion, and migration activity in the human Jurkat T-lymphoma cell line. Cancer Invest., 2008, Vol. 26, pp. 689-697.

13. Chikte S., Panchal N., Warnes G. Use of LysoTracker dyes: A flow cytometric study of autophagy. Cytometry A, 2014, Vol. 85, no. 2, pp. 169-178.

14. Ermis M., Akkaynak D., Chen P., Demirci U., Hasirci V. A high throughput approach for analysis of cell nuclear deformability at single cell level. Sci. Rep., 2016, 6, 36917. doi: 10.1038/srep36917.

15. Gao P., Wange R.L., Zhang N. Oppenheim J.J., Howard O.M.Z. Negative regulation of CXCR4-mediated chemotaxis by the lipid phosphatase activity of tumor suppressor PTEN. Blood, 2005, Vol. 106, no. 8, pp. $2619-2626$.

16. Khlusov I.A., Litvinova L.S., Shupletsova V.V., Khaziakhmatova O.G., Malashchenko V.V., Yurova K.A., Shunkin E.O., Krivosheev V.V., Porokhova E.D., Sizikova A.E., Safiullina L.A., Legostaeva E.V., Komarova E.G., Sharkeev Yu.P. Costimulatory effect of rough calcium phosphate coating and blood mononuclear cells on adiposederived mesenchymal stem cells in vitro as a model of in vivo tissue repair. Materials, 2020, Vol. 13, no. 19, 4398. doi:10.3390/ma13194398.

17. Khlusov I., Litvinova L., Shupletsova V., Khaziakhmatova O., Melashchenko E., Yurova K., Leitsin V., Khlusova M., Pichugin V., Sharkeev Y. Rough titanium oxide coating prepared by micro-arc oxidation causes downregulation of hTERT expression, molecular presentation, and cytokine secretion in tumor Jurkat T cells. Materials, 2018, Vol. 11, 360. doi: 10.3390/ma11030360.

18. Kuban-Jankowska A., Knap N., Gorska M., Popowska U., Wozniak M. Protein tyrosine phosphatase CD45 as a molecular biosensor of hydrogen peroxide generation in cell culture media. Biochem. Biophys. Res. Commun., 2011, Vol. 415, no. 2, pp. 270-273.

19. Lewinska A., Wnuk M., Slota E., Bartosz G. Total anti-oxidant capacity of cell culture media. Clin. Exp. Pharmacol. Physiol., 2007, Vol. 34, no. 8, pp. 781-786.

20. Liao H.F., Chen Y.J., Chou C.H., Wang F.W., Kuo C.D. Norcantharidin induces cell cycle arrest and inhibits progression of human leukemic Jurkat $\mathrm{T}$ cells through mitogen-activated protein kinase-mediated regulation of interleukin-2 production. Toxicol. Vitro, 2011, Vol. 25, pp. 206-212.

21. Litvinova L.S., Khaziakhmatova O.G., Shupletsova V.V., Yurova K.A., Malashchenko V.V., Shunkin E.O., Ivanov P.A., Komarova E.G., Chebodaeva V.V., Porokhova E.D., Gereng E.A., Khlusov I.A. Calcium phosphate coating prepared by microarc oxidation affects htert expression, molecular presentation, and cytokine secretion in tumor-derived jurkat T Cells. Materials, 2020, Vol. 13, no. 19, 4307. doi: 10.3390/ma13194307.

22. Luongo D., Russo R., Balestrieri A., Marzocco S., Bergamo P., Severino L. In vitro study of AFB1 and AFM1 effects on human lymphoblastoid Jurkat T-cell model. J. Immunotoxicol., 2014, Vol.11, pp. 353-358.

23. Perron M., Saragovi H.U. Inhibition of CD45 Phosphatase activity induces cell cycle arrest and apoptosis of CD45 lymphoid tumors ex vivo and in vivo. Mol. Pharmacol., 2018, Vol. 93, no. 6, pp. 575-580.

24. Poggi P., Mirabella R., Neri S., Assirelli E., Dolzani P., Mariani E., Calder P.C., Chatgilialoglu A. Membrane fatty acid heterogeneity of leukocyte classes is altered during in vitro cultivation but can be restored with ad-hoc lipid supplementation. Lipids Health Dis., 2015, Vol. 14, 165. doi: 10.1186/s12944-015-0166-3.

25. Polacheck W.J., Zervantonakis I.K., Kamm R.D. Tumor cell migration in complex microenvironments. Cell. Mol. Life Sci., 2013, Vol. 70, pp. 1335-1356. 
26. Stevens M.J., Donato L.J., Lower S.K., Sahai N. Oxide-dependent adhesion of the Jurkat line of T lymphocytes. Langmuir, 2009, Vol. 25, pp. 6270-6278.

27. Tuomela S., Autio R., Buerki-Thurnherr T., Arslan O., Kunzmann A., Andersson-Willman B., Wick P., Mathur S., Scheynius A., Krug H.F., Fadeel B., Lahesmaa R. Gene expression profiling of immune-competent human cells exposed to engineered zinc oxide or titanium dioxide nanoparticles. PLoS One, 2013, Vol. 8, e68415. doi: 10.1371/journal.pone.0068415.

28. Yuan Y., Lu X., Chen X., Shao H., Huang S. Jagged1 contributes to the drug resistance of Jurkat cells in contact with human umbilical cord-derived mesenchymal stem cells. Oncol. Lett., 2013, Vol. 6, no. 4, pp. 1000-1006.

\begin{abstract}
Авторы:
Литвинова Л.С. - д.м.н., руководитель центра иммунологии и клеточных биотехнологий ФГАОУ ВО «Балтийский федеральный университет имени И. Канта», г. Калининград, Россия

Юрова К.А. - к.м.н., старший научный сотрудник иентра иммунологии и клеточных биотехнологий ФГАОУ ВО «Балтийский федеральный университет имени И. Канта», г. Калининград, Россия
\end{abstract}

Газатова Н.Д. - к.б.н., старший научный сотрудник центра иммунологии и клеточных биотехнологий ФГАОУ ВО «Балтийский федеральный университет имени И. Канта», г. Калининград, Россия

Шуплецова В.В. - к.б.н., старший научный сотрудник центра иммунологии и клеточных биотехнологий ФГАОУ ВО «Балтийский федеральный университет имени И. Канта», г. Калининград, Россия

Хазиахматова О.Г. - к.б.н., научный сотрудник центра иммунологии и клеточных биотехнологий ФГАОУ ВО «Балтийский федеральный университет имени И. Канта», г. Калининград, Россия

Малащенко В.В. - научный сотрудник центра иммунологии и клеточных биотехнологий ФГАОУ ВО «Балтийский федеральный университет имени И. Канта», г. Калининград, Россия

Шунькин Е.О. - младший научный сотрудник центра иммунологии и клеточных биотехнологий ФГАОУ ВО «Балтийский федеральный университет имени И. Канта», г. Калининград, Россия

\section{Authors: \\ Litvinova L.S., PhD, MD (Medicine), Head, Center of Immunology and Cell Biotechnologies, I. Kant Baltic Federal University, Kaliningrad, Russian Federation}

Yurova K.A., PhD (Medicine), Senior Research Associate, Center of Immunology and Cell Biotechnologies, I. Kant Baltic Federal University, Kaliningrad, Russian Federation

Gazatova N.D., PhD (Biology), Senior Research Associate, Center of Immunology and Cell Biotechnologies, I. Kant Baltic Federal University, Kaliningrad, Russian Federation

Shchupletsova V.V., PhD (Biology), Senior Research Associate, Center of Immunology and Cell Biotechnologies, I. Kant Baltic Federal University, Kaliningrad, Russian Federation

Khasiakhmatova O.G., PhD (Biology), Research Associate, Center of Immunology and Cell Biotechnologies, I. Kant Baltic Federal University, Kaliningrad, Russian Federation

Malashchenko V.V., Research Associate, Center of Immunology and Cell Biotechnologies, I. Kant Baltic Federal University, Kaliningrad, Russian Federation

Shunkin E.O., Junior Research Associate, Center of Immunology and Cell Biotechnologies, I. Kant Baltic Federal University, Kaliningrad, Russian Federation 
Тодосенко Н.М. - к.б.н., старший научный сотрудник иентра иммунологии и клеточных биотехнологий ФГАОУ ВО «Балтийский федеральный университет имени И. Канта», г. Калининград, Россия

Мелащенко Е.C. - младший научный сотрудник центра иммунологии и клеточных биотехнологий ФГАОУ ВО «Балтийский федеральный университет имени И. Канта», г. Калининград, Россия

Хлусова М.Ю. - д.м.н., доцент кафедры патофизиологии ЛФ ФГБОУ ВО «Сибирский государственный медицинский университет», г. Томск, Россия

Хлусов И.А. - д.м.н., главный научный сотрудник иентра иммунологии и клеточных биотехнологий ФГАОУ ВО «Балтийский федеральный университет имени И. Канта», г. Калининград; профессор кафедры морфологии и общей патологии ФГБОУ ВО «Сибирский государственный медицинский университет»;

профессор Исследовательской школы химических и биомедицинских технологий ФГАОУ ВО «Национальный исследовательский Томский политехнический университет», г. Томск, Россия

Поступила 14.10.2020

Принята к печати 20.04.2021
Todosenko N.M., PhD (Biology), Senior Research Associate, Center of Immunology and Cell Biotechnologies, I. Kant Baltic Federal University, Kaliningrad, Russian Federation

Melashchenko E.S., Junior Research Associate, Center of Immunology and Cell Biotechnologies, I. Kant Baltic Federal University, Kaliningrad, Russian Federation

Khlusova M.Yu., PhD, MD (Medicine), Associate Professor, Department of Pathological Physiology, Siberian State Medical University, Tomsk, Russian Federation

Khlusov I.A., PhD, MD (Medicine), Main Research Associate, Center of Immunology and Cell Biotechnologies, I. Kant Baltic Federal University, Kaliningrad; Professor, Department of Morphology and General Pathology, Siberian State Medical University, Tomsk; Professor, Research School of Chemical and Biomedical Technologies, Tomsk Polytechnic University, Tomsk, Russian Federation

Received 14.10.2020

Accepted 20.04.2021 